Article

\title{
Phenolic Composition Stability and Antioxidant Activity of Sour Cherry Liqueurs
}

\author{
Anna Sokół-Łętowska ${ }^{1, *(1)}$, Alicja Z. Kucharska ${ }^{1}{ }^{(D)}$, Antoni Szumny ${ }^{2}{ }^{(0)}$, Katarzyna Wińska ${ }^{2}$ \\ and Agnieszka Nawirska-Olszańska ${ }^{1}$ \\ 1 Department of Fruit, Vegetable and Plant Nutraceutical Technology, Wrocław University of Environmental \\ and Life Sciences, J. Chełmońskiego 37, 51-630 Wrocław, Poland; alicja.kucharska@upwr.edu.pl (A.Z.K.); \\ agnieszka.nawirska-olszanska@upwr.edu.pl (A.N.-O.) \\ 2 Department of Chemistry, Wrocław University of Environmental and Life Sciences, J. Chełmońskiego 37, \\ 51-630 Wrocław, Poland; antoni.szumny@upwr.edu.pl (A.S.); katarzyna.winska@upwr.edu.pl (K.W.) \\ * Correspondence: anna.sokol-letowska@upwr.edu.pl; Tel.: +48-71-320-7707
}

Academic Editors: Isabel C. F. R. Ferreira and Nancy D. Turner

Received: 7 August 2018; Accepted: 27 August 2018; Published: 27 August 2018

\begin{abstract}
The aim of the study was to evaluate changes of phenolic and anthocyanin contents, antioxidant activity, aroma compounds and color of sour cherry liqueurs with and without sugar during 6 months of storage at temperatures of $15^{\circ} \mathrm{C}$ and $30^{\circ} \mathrm{C}$. Contents of phenolic compounds (HPLC, UPLC-MS) and antiradical activity (ABTS) changes were measured. Color changes were measured by an objective method (ColorQuest XE). During storage fluctuations of phenolic compounds and antioxidant activity content were observed. The content of substances which react with Folin-Ciocalteu reagent was comparable before and after 24 weeks. During the 24 weeks of storage, the highest average antioxidant activity against ABTS radicals was shown by sour cherry liqueurs without sugar, stored at $15{ }^{\circ} \mathrm{C}$. Quicker degradation of anthocyanins was observed in liqueurs without sugar, stored at $30{ }^{\circ} \mathrm{C}\left(\mathrm{t}_{1 / 2}-5.9\right.$ weeks in liqueurs with sugar and 6.6 weeks in liqueurs without sugar). Better stability of red color was observed in liqueurs with sugar, stored at $15{ }^{\circ} \mathrm{C}$. The content of the dominant aroma compound, benzaldehyde, increased during storage. Long-term storage and sugar addition decreases color attributes but increases organoleptic value without of great influence on antioxidant activity. Studies on a half-year period of liqueur storage showed that their characteristic features are almost unchanged if stored at $15^{\circ} \mathrm{C}$ and without sugar added, but organoleptic properties were better in samples stored at $30^{\circ} \mathrm{C}$.
\end{abstract}

Keywords: liqueurs; sour cherry; phenolic compounds; anthocyanins; aromatic compounds; antioxidant activity

\section{Introduction}

Fruit liqueurs are traditional alcoholic beverages made by maceration of fruits in an aqueous solution of ethanol. The way they are prepared is important to achieve the proper flavor and aroma of liqueurs. Strength and the proportions of alcohol to the components, the method of preparation as well as time of maceration may vary (from several days to several months) [1-4].

Liqueurs and tinctures have been used in folk medicine for many years. Today, it is known that the therapeutic effects of liqueurs are associated with the presence of phenolic compounds, which are valuable components of the diet. Recent dietary recommendations permit small amounts of alcoholic beverages. According to the recommendations of the Dietary Guidelines for Americans for 2010-2015 and 2015-2020 [5,6], moderate consumption of alcoholic beverages may have beneficial effects on human health. Phenolic compounds are dominant compounds antioxidants in alcoholic beverages 
made from fruit. Their biological activity has been repeatedly confirmed. As a component of liqueurs, they are able (to some extent) to counter the pro-oxidant activity of alcohol [7].

Cherry fruit is characterized by a red color, juicy flesh, a sour taste and a pleasant aroma. Therefore, in many countries sour cherry liqueurs are especially popular. Cherries contain more than $200 \mathrm{mg}$ of polyphenols $/ 100 \mathrm{~g}$ of fruit. They are rich in flavonoids represented by anthocyanins (mainly glycosides of cyanidin), flavan-3-ols (catechin, epicatechin), flavonols (rutin, quercetin, kaempferol) and phenolic acids: chlorogenic, $p$-coumaric, caffeic. They are one of the few fruits to contain melatonin [8-11].

Cherry stones contain cyanogenic glycosides, including amygdalin. These compounds are characterized by potential toxicity after hydrolysis into hydrogen cyanide. During the process of maceration of fruit, they can be extracted into the liqueur. The concentration of these toxic ingredients in the finished product depends on the way and time of fruit maceration, but also on the time the liqueurs are stored.

Due to the amygdalin content, especially in stones, sour cherry liqueurs should be prepared from partially pitted cherries or in a short period of extraction time to avoid the presence of excessive amount of cyanogenic glycosides in the liqueur. According to Sokóf-Łętowska [12] the content of HCN decreased 5-10-fold during prolonged storage. Leaving a small amount of kernels in the solution leads to release of hydrocyanic acid from stones and imparts a gentle bitter almond flavor to the beverage.

There are very few research papers on the characteristics of fruit liqueurs. Nikicevic et al. investigated the flavors of cherry spirits made from five Serbian varieties of cherries after fruit fermentation. Ethyl octanoate and ethyl decanoate were determined in the highest concentrations in distillates [13]. Rodtjer et al. [14] investigated phenolic compounds in an aromatic bitter and a cherry liqueur by high-performance liquid chromatography (HPLC) with electrochemical detection. There is a general lack of research on phenolic compound content changes during storage. In our previous study [15] we compared ten liqueurs made from red fruit and changes in contents of the main phenolic groups during storage.

In the production of fruit liqueurs, different technologies are used (e.g., using the different order of adding ingredients, running the process at different temperatures, etc.). It is important to maintain the high quality of the product. These issues have not been tested so far, therefore it was decided to determine whether the addition of sugar during the production of liqueurs and storage temperature will affect the final quality of the product. The purpose of the work was to determine whether and how the sugar added to the fruit extract influences the quality of the obtained liqueur.

The second aim of this study was to identify phenolic compounds and quantify the main anthocyanins, flavonoids, and phenolic acids that were found in sour cherry liqueurs stored for six months at 15 and $30^{\circ} \mathrm{C}$.

\section{Results}

\subsection{Identification of Phenolic Compounds}

Compounds identified before and after storage of cherry liqueurs are presented in Tables S1 and S2, and Figure S1. However, although LC-TOF-MS/MS was used for identification, the information provided by UV absorptions, retention times, mass and MS/MS spectra were not sufficient to determine the identity of all compounds. Identified compounds are in agreement with earlier research [16-18]. During storage some of the compounds disappeared or underwent rearrangements. In samples with added sugar partial disappearance of caffeoylquinic acid derivatives, protocatechuic acid hexoside and some of the dimeric and trimeric flavanols occurred. At $30^{\circ} \mathrm{C}$ the isomer of coumaroylquinic acid appeared, but flavanol dimers and monomers disappeared, probably due to rearrangement of the moieties to afford polymeric forms. 


\subsubsection{Phenolic Acids}

Directly after preparation of liqueurs $188.4-203.4 \mu \mathrm{g} / \mathrm{mL}$ of phenolic acids were determined (Table 1). The main phenolic acids in sour cherry liqueurs were $p$-coumaroylquinic (about 53.3\%), neochlorogenic $(25.1 \%)$ and chlorogenic $(21.6 \%)$ acids. Hydroxycinnamic acids were quite stable during storage. After 6 months of storage a concentration of 165.1-177.0 $\mu \mathrm{g} / \mathrm{mL}$ was determined. In samples without and with sugar added the phenolic acid content was $176.0-177.0 \mu \mathrm{g} / \mathrm{mL}$ and $165.0-170.7 \mu \mathrm{g} / \mathrm{mL}$, respectively, that is about $4-7 \%$ and $15-17 \%$ less than the initial content, respectively. Losses of coumaroylquinic acid—the main phenolic acid in cherry liqueur-were slightly greater than those of other acids (7.4-20.7\%). Similar results were obtained in a previous study by Kallithraka et al. on changes in phenolic composition of white wines during storage [19].

Table 1. Changes in phenolic acids content $(\mu \mathrm{g} / \mathrm{mL})$ during cherry liqueurs storage.

\begin{tabular}{|c|c|c|c|c|c|}
\hline Compounds & Week & \multicolumn{2}{|c|}{ Temperature $15^{\circ} \mathrm{C}$} & \multicolumn{2}{|c|}{ Temperature $30^{\circ} \mathrm{C}$} \\
\hline \multirow[b]{2}{*}{ Neochlorogenic acid } & 6 & $47.66 \pm 0.40$ & $50.87 \pm 0.11$ & $46.16 \pm 0.49$ & $50.16 \pm 0.47$ \\
\hline & 12 & $45.88 \pm 0.43$ & $49.27 \pm 0.13$ & $43.83 \pm 0.59$ & $46.47 \pm 0.61$ \\
\hline \multirow{5}{*}{ Coumaroylquinic acid } & 0 & $100.35 \pm 0.09$ & $108.24 \pm 1.13$ & $101.93 \pm 0.65$ & $107.52 \pm 0.53$ \\
\hline & 6 & $100.98 \pm 0.23$ & $108.03 \pm 0.02$ & $98.93 \pm 0.25$ & $106.72 \pm 0.72$ \\
\hline & 12 & $97.82 \pm 0.83$ & $105.16 \pm 0.74$ & $94.29 \pm 1.08$ & $99.48 \pm 0.66$ \\
\hline & 18 & $94.62 \pm 0.11$ & $96.81 \pm 1.15$ & $89.74 \pm 0.52$ & $83.8 \pm 1.19$ \\
\hline & 24 & $92.9 \pm 1.22$ & $92.98 \pm 0.34$ & $89.53 \pm 0.00$ & $85.25 \pm 1.12$ \\
\hline \multirow{2}{*}{ Chlorogenic acid } & 18 & $38.63 \pm 0.51$ & $40.59 \pm 0.03$ & $44.46 \pm 0.30$ & $36.85 \pm 0.16$ \\
\hline & 24 & $37.55 \pm 0.19$ & $36.9 \pm 0.26$ & $44.06 \pm 0.04$ & $37.27 \pm 0.44$ \\
\hline \multirow{5}{*}{ Sum of Phenolic acids } & 0 & $188.40 \pm 1.15$ & $203.43 \pm 0.52$ & $191.36 \pm 1.76$ & $201.36 \pm 0.00$ \\
\hline & 6 & $189.41 \pm 2.25$ & $202.22 \pm 0.31$ & $185.03 \pm 1.99$ & $200.31 \pm 0.11$ \\
\hline & 12 & $183.49 \pm 2.57$ & $197.41 \pm 1.40$ & $176.02 \pm 2.14$ & $186.73 \pm 0.77$ \\
\hline & 18 & $179.72 \pm 1.17$ & $179.15 \pm 0.35$ & $178.53 \pm 1.59$ & $163.29 \pm 1.52$ \\
\hline & 24 & $176.18 \pm 0.42$ & $170.69 \pm 1.86$ & $177.03 \pm 1.35$ & $165.06 \pm 1.63$ \\
\hline
\end{tabular}

${ }^{1}$ Values are expressed as the mean $(n=3) \pm$ standard deviation.

\subsubsection{Flavanols}

(-)-Epicatechin, procyanidins B1, B2, C1 and other unidentified dimers, trimers and tetramers were present in liqueurs (Table 2). The concentration of the main flavan 3-ol-procyanidin B2-was 80.5-90.9 $\mu \mathrm{g} / \mathrm{mL}$. Flavanols were unstable during storage and their content decreased significantly during 24 weeks. After storage at $15^{\circ} \mathrm{C}$ the content of procyanidin B2 decreased to $53.2 \mu \mathrm{g} / \mathrm{mL}$ and $39.6 \mu \mathrm{g} / \mathrm{mL}$. At $30^{\circ} \mathrm{C}$ complete degradation was observed after 18 weeks (the sample with sugar).

In samples stored at $30{ }^{\circ} \mathrm{C}$ the content of flavanols increased or decreased in the first 6-12 weeks and then consequently decreased due to the disappearance of monomers and dimers, faster in liqueurs with added sugar. The content of trimers and tetramers decreased, but slower than that of the monomers and dimers, probably due to polymerization of monomers and dimers, because near to 6-12 weeks of storage the content of trimers and tetramers increased and later decreased to $25-30 \%$ of the initial values. The total flavanol content in stored liqueurs was $4.7-5.9 \%$ of the initial value (at $30{ }^{\circ} \mathrm{C}$ ) and $78.5 \%$ and $42.3 \%$ of initial values in samples stored at $15{ }^{\circ} \mathrm{C}$ without and with sugar respectively. Fluctuations of flavanol contents were observed during storage, as is seen for example for 
the sum of epicatechin and an unknown dimer (Table 2) and the sum of procyanidin C1 and a tetramer. This may be the result of rearrangement and/or hydrolysis of dimer moieties.

Table 2. Changes in flavanols content $(\mu \mathrm{g} / \mathrm{mL})$ during cherry liqueurs storage.

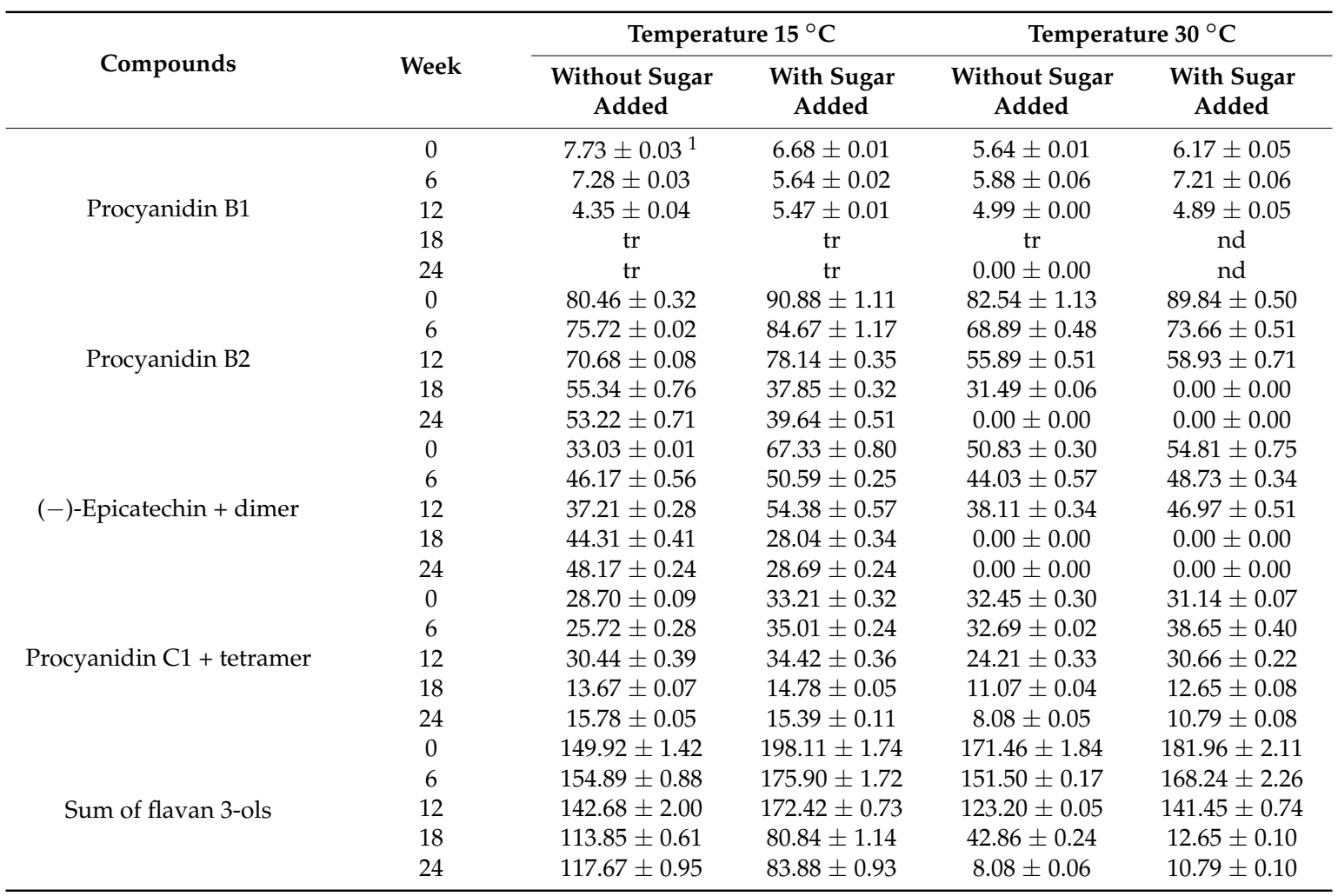

${ }^{1}$ Values are expressed as the mean $(n=3) \pm$ standard deviation, tr-traces, nd-not detected.

\subsubsection{Flavonols}

An amount of 139.7 to $158.6 \mu \mathrm{g} / \mathrm{mL}$ of flavonols was determined in liqueurs before storage and from 105.0 to $130.0 \mu \mathrm{g} / \mathrm{mL}$ after 24 weeks of storage (Table 3). Flavonols were more stable during storage than other groups of phenolic compounds. Our results are in agreement with data published by Nowicka and Wojdyło [16]. Differences in behavior of samples stored at $15^{\circ} \mathrm{C}$ and $30{ }^{\circ} \mathrm{C}$ and with/without sugar added were observed. In liqueurs prepared without sugar more flavonols remained after storage- $-71.8 \%$ and $93.2 \%$ of initial content (at $30{ }^{\circ} \mathrm{C}$ and $15{ }^{\circ} \mathrm{C}$ respectively) - whilst in samples with sugar added $68.3 \%$ and $82.0 \%$ of the initial sum of flavonols was determined. The derivatives of kaempferol, quercetin and isorhamnetin were identified. The main flavonol was quercetin 3-rutinoside (48.2-52.2 $\mathrm{gg} / \mathrm{mL})$, and that compound was quite stable during storage, because after storage liqueurs contained $43.6-46.6 \mu \mathrm{g} / \mathrm{mL}$. A similar observation was made for other flavonols. The content of quercetin increased after 24 weeks from $0.9 \mu \mathrm{g} / \mathrm{mL}$ to $2.3-4.0 \mu \mathrm{g} / \mathrm{mL}$, increasing most in samples with sugar stored at $30^{\circ} \mathrm{C}$. It may be the result of hydrolysis of quercetin derivatives, as sour cherry liqueurs have high acidity, which favors such reactions. 
Table 3. Changes in flavonols content $(\mu \mathrm{g} / \mathrm{mL})$ during cherry liqueurs storage.

\begin{tabular}{|c|c|c|c|c|c|}
\hline \multirow{2}{*}{ Compounds } & \multirow[b]{2}{*}{ Week } & \multicolumn{2}{|c|}{ Temperature $15^{\circ} \mathrm{C}$} & \multicolumn{2}{|c|}{ Temperature $30^{\circ} \mathrm{C}$} \\
\hline & & $\begin{array}{c}\text { Without Sugar } \\
\text { Added }\end{array}$ & $\begin{array}{c}\text { With Sugar } \\
\text { Added }\end{array}$ & $\begin{array}{c}\text { Without Sugar } \\
\text { Added }\end{array}$ & $\begin{array}{l}\text { With Sugar } \\
\text { Added }\end{array}$ \\
\hline \multirow{5}{*}{ Kaempferol-trihexoside 1} & 0 & $22.29 \pm 0.14^{1}$ & $28.35 \pm 0.18$ & $25.63 \pm 0.31$ & $28.16 \pm 0.12$ \\
\hline & 6 & $20.41 \pm 0.28$ & $24.74 \pm 0.07$ & $13.83 \pm 0.13$ & $16.18 \pm 0.19$ \\
\hline & 12 & $18.29 \pm 0.01$ & $21.79 \pm 0.15$ & $8.47 \pm 0.10$ & $10.28 \pm 0.09$ \\
\hline & 18 & $22.07 \pm 0.14$ & $18.94 \pm 0.03$ & $7.32 \pm 0.06$ & $5.34 \pm 0.06$ \\
\hline & 24 & $18.86 \pm 0.16$ & $16.87 \pm 0.17$ & $3.93 \pm 0.05$ & $3.54 \pm 0.04$ \\
\hline \multirow{5}{*}{ Kaempferol-trihexoside 2} & 0 & $7.63 \pm 0.01$ & $11.45 \pm 0.14$ & $10.42 \pm 0.10$ & $11.29 \pm 0.05$ \\
\hline & 6 & $6.55 \pm 0.08$ & $9.59 \pm 0.12$ & $4.39 \pm 0.04$ & $5.38 \pm 0.06$ \\
\hline & 12 & $7.91 \pm 0.07$ & $7.83 \pm 0.04$ & $1.12 \pm 0.00$ & $2.05 \pm 0.03$ \\
\hline & 18 & $6.27 \pm 0.05$ & $6.90 \pm 0.03$ & $1.64 \pm 0.00$ & $5.34 \pm 0.01$ \\
\hline & 24 & $0.00 \pm 0.00$ & $5.91 \pm 0.06$ & $0.00 \pm 0.00$ & $3.54 \pm 0.03$ \\
\hline \multirow{5}{*}{ Kaempferol-dihexoside } & 0 & $16.98 \pm 0.01$ & $18.38 \pm 0.01$ & $17.24 \pm 0.05$ & $18.20 \pm 0.23$ \\
\hline & 6 & $17.23 \pm 0.01$ & $18.53 \pm 0.01$ & $16.84 \pm 0.08$ & $18.40 \pm 0.01$ \\
\hline & 12 & $16.64 \pm 0.07$ & $17.97 \pm 0.06$ & $16.11 \pm 0.13$ & $17.35 \pm 0.09$ \\
\hline & 18 & $15.80 \pm 0.02$ & $15.82 \pm 0.07$ & $15.44 \pm 0.05$ & $15.12 \pm 0.06$ \\
\hline & 24 & $15.51 \pm 0.15$ & $15.72 \pm 0.19$ & $15.34 \pm 0.11$ & $15.25 \pm 0.09$ \\
\hline \multirow{5}{*}{ Quercetin-rutinoside-rhamnoside } & 0 & $3.79 \pm 0.01$ & $3.54 \pm 0.05$ & $3.34 \pm 0.01$ & $3.51 \pm 0.04$ \\
\hline & 6 & $3.35 \pm 0.01$ & $3.58 \pm 0.03$ & $3.27 \pm 0.01$ & $3.56 \pm 0.02$ \\
\hline & 12 & $3.21 \pm 0.01$ & $3.44 \pm 0.04$ & $3.14 \pm 0.02$ & $3.43 \pm 0.00$ \\
\hline & 18 & $3.32 \pm 0.00$ & $3.28 \pm 0.02$ & $3.32 \pm 0.01$ & $2.57 \pm 0.03$ \\
\hline & 24 & $3.28 \pm 0.03$ & $3.29 \pm 0.04$ & $2.83 \pm 0.03$ & $2.53 \pm 0.02$ \\
\hline \multirow{5}{*}{ Quercetin-rutinoside } & 0 & $48.28 \pm 0.20$ & $52.15 \pm 41$ & $48.16 \pm 0.27$ & $51.71 \pm 0.34$ \\
\hline & 6 & $48.36 \pm 0.40$ & $52.21 \pm 0.52$ & $47.58 \pm 0.65$ & $52.78 \pm 0.32$ \\
\hline & 12 & $47.01 \pm 0.08$ & $51.06 \pm 0.60$ & $46.28 \pm 0.63$ & $49.23 \pm 0.02$ \\
\hline & 18 & $45.64 \pm 0.54$ & $46.61 \pm 0.65$ & $43.64 \pm 0.30$ & $43.78 \pm 0.03$ \\
\hline & 24 & $44.29 \pm 0.28$ & $46.30 \pm 0.10$ & $43.35 \pm 0.59$ & $46.69 \pm 0.22$ \\
\hline \multirow{5}{*}{ Quercetin-glucoside } & 0 & $5.90 \pm 0.07$ & $6.48 \pm 0.07$ & $5.37 \pm 0.07$ & $6.55 \pm 0.07$ \\
\hline & 6 & $5.52 \pm 0.03$ & $6.57 \pm 0.03$ & $5.65 \pm 0.07$ & $6.71 \pm 0.00$ \\
\hline & 12 & $6.04 \pm 0.01$ & $6.32 \pm 0.01$ & $6.17 \pm 0.01$ & $5.91 \pm 0.06$ \\
\hline & 18 & $5.83 \pm 0.05$ & $5.91 \pm 0.06$ & $5.79 \pm 0.04$ & $5.64 \pm 0.07$ \\
\hline & 24 & $5.68 \pm 0.08$ & $6.01 \pm 0.08$ & $6.01 \pm 0.05$ & $6.26 \pm 0.02$ \\
\hline \multirow{5}{*}{ Kaempferol-rutinoside } & 0 & $12.42 \pm 0.02$ & $14.19 \pm 0.18$ & $13.43 \pm 0.00$ & $14.25 \pm 0.06$ \\
\hline & 6 & $13.32 \pm 0.04$ & $14.46 \pm 0.11$ & $13.26 \pm 0.13$ & $14.52 \pm 0.07$ \\
\hline & 12 & $12.90 \pm 0.06$ & $14.17 \pm 0.18$ & $12.72 \pm 0.08$ & $13.60 \pm 0.06$ \\
\hline & 18 & $12.39 \pm 0.10$ & $12.72 \pm 0.04$ & $11.81 \pm 0.12$ & $12.02 \pm 0.11$ \\
\hline & 24 & $13.92 \pm 0.10$ & $12.48 \pm 0.02$ & $11.63 \pm 0.12$ & $12.68 \pm 0.13$ \\
\hline \multirow{5}{*}{ Isorhamnetine-rutinoside } & 0 & $20.92 \pm 0.24$ & $23.11 \pm 0.20$ & $21.58 \pm 0.21$ & $22.75 \pm 0.03$ \\
\hline & 6 & $21.41 \pm 0.14$ & $23.25 \pm 0.16$ & $21.37 \pm 0.14$ & $23.33 \pm 0.05$ \\
\hline & 12 & $20.77 \pm 0.06$ & $22.68 \pm 0.15$ & $20.45 \pm 0.20$ & $21.93 \pm 0.23$ \\
\hline & 18 & $20.38 \pm 0.09$ & $20.76 \pm 0.15$ & $19.46 \pm 0.07$ & $19.75 \pm 0.05$ \\
\hline & 24 & $20.11 \pm 0.04$ & $20.46 \pm 0.19$ & $19.30 \pm 0.10$ & $12.68 \pm 0.16$ \\
\hline \multirow{5}{*}{ Quercetin } & 0 & $0.88 \pm 0.00$ & $0.90 \pm 0.00$ & $0.97 \pm 0.00$ & $0.94 \pm 0.00$ \\
\hline & 6 & $1.62 \pm 0.00$ & $1.53 \pm 0.00$ & $2.01 \pm 0.02$ & $2.43 \pm 0.02$ \\
\hline & 12 & $1.15 \pm 0.01$ & $1.47 \pm 0.00$ & $1.76 \pm 0.01$ & $3.38 \pm 0.01$ \\
\hline & 18 & $2.17 \pm 0.02$ & $2.06 \pm 0.03$ & $2.04 \pm 0.01$ & $2.76 \pm 0.03$ \\
\hline & 24 & $2.30 \pm 0.03$ & $2.97 \pm 0.03$ & $2.58 \pm 0.00$ & $4.34 \pm 0.05$ \\
\hline \multirow{5}{*}{ Sum of flavonols } & 0 & $139.73 \pm 0.79$ & $158.56 \pm 1.48$ & $146.16 \pm 0.54$ & $157.38 \pm 0.87$ \\
\hline & 6 & $138.85 \pm 0.04$ & $154.45 \pm 1.62$ & $128.21 \pm 0.33$ & $143.30 \pm 1.30$ \\
\hline & 12 & $132.56 \pm 0.73$ & $146.72 \pm 0.62$ & $116.23 \pm 0.77$ & $127.18 \pm 1.10$ \\
\hline & 18 & $135.50 \pm 1.15$ & $133.02 \pm 0.19$ & $110.46 \pm 0.41$ & $112.33 \pm 1.38$ \\
\hline & 24 & $130.21 \pm 1.10$ & $130.01 \pm 0.96$ & $104.97 \pm 1.05$ & $107.52 \pm 1.46$ \\
\hline
\end{tabular}

\footnotetext{
${ }^{1}$ Values are expressed as the mean $(n=3) \pm$ standard deviation
} 


\subsubsection{Anthocyanins}

The content of anthocyanins immediately after preparation of sour cherry liqueurs was $216.8-230.8 \mu \mathrm{g} / \mathrm{mL}$ (Table 4). As expected, the amount of anthocyanins decreased significantly during storage, to $39.1-39.8 \%$ of the initial value in samples stored at $15^{\circ} \mathrm{C}$ and to $6.5-6.9 \%$ in samples stored at $30{ }^{\circ} \mathrm{C}$. The content of individual anthocyanins decreased to $58.4-33.1 \%$ at $15^{\circ} \mathrm{C}$ and to $2.0 \%-7.9 \%$ of the initial value at $30^{\circ} \mathrm{C}$.

Table 4. Changes in anthocyanins content $(\mu \mathrm{g} / \mathrm{mL})$ during cherry liqueurs storage.

\begin{tabular}{|c|c|c|c|c|c|}
\hline \multirow{2}{*}{ Compounds } & \multirow[b]{2}{*}{ Week } & \multicolumn{2}{|c|}{ Temperature $15^{\circ} \mathrm{C}$} & \multicolumn{2}{|c|}{ Temperature $30^{\circ} \mathrm{C}$} \\
\hline & & $\begin{array}{c}\text { Without Sugar } \\
\text { Added }\end{array}$ & $\begin{array}{l}\text { With Sugar } \\
\text { Added }\end{array}$ & $\begin{array}{c}\text { Without Sugar } \\
\text { Added }\end{array}$ & $\begin{array}{l}\text { With Sugar } \\
\text { Added }\end{array}$ \\
\hline \multirow{5}{*}{ Cyanidin 3-O-sophoroside } & 0 & $19.11 \pm 0.13^{1}$ & $20.21 \pm 0.10$ & $18.98 \pm 0.01$ & $20.15 \pm 0.24$ \\
\hline & 6 & $15.57 \pm 0.07$ & $17.17 \pm 0.18$ & $7.95 \pm 0.04$ & $9.37 \pm 0.10$ \\
\hline & 12 & $12.32 \pm 0.01$ & $14.57 \pm 0.15$ & $3.81 \pm 0.02$ & $4.74 \pm 0.01$ \\
\hline & 18 & $8.12 \pm 0.00$ & $12.50 \pm 0.16$ & $1.57 \pm 0.02$ & $2.81 \pm 0.02$ \\
\hline & 24 & $6.91 \pm 0.09$ & $11.80 \pm 0.06$ & $0.88 \pm 0.01$ & $1.59 \pm 0.01$ \\
\hline \multirow{5}{*}{$\begin{array}{l}\text { Cyanidin 3-O-glucosyl } \\
\text { rutinoside }\end{array}$} & 0 & $135.23 \pm 0.84$ & $143.26 \pm 1.07$ & $134.83 \pm 1.79$ & $142.62 \pm 1.03$ \\
\hline & 6 & $113.56 \pm 0.29$ & $125.12 \pm 0.85$ & $64.42 \pm 0.91$ & $75.92 \pm 0.24$ \\
\hline & 12 & $92.85 \pm 0.30$ & $105.45 \pm 1.31$ & $35.04 \pm 0.12$ & $43.86 \pm 0.61$ \\
\hline & 18 & $65.27 \pm 0.61$ & $55.17 \pm 0.71$ & $17.06 \pm 0.16$ & $15.50 \pm 0.14$ \\
\hline & 24 & $56.14 \pm 0.71$ & $48.93 \pm 0.23$ & $11.01 \pm 0.08$ & $9.82 \pm 0.01$ \\
\hline \multirow{5}{*}{ Cyanidin 3-O-glucoside } & 0 & $5.18 \pm 0.01$ & $6.06 \pm 0.08$ & $5.54 \pm 0.01$ & $6.13 \pm 0.01$ \\
\hline & 6 & $4.30 \pm 0.05$ & $4.77 \pm 0.03$ & $1.73 \pm 0.01$ & $2.30 \pm 0.01$ \\
\hline & 12 & $3.17 \pm 0.02$ & $4.55 \pm 0.01$ & $0.68 \pm 0.00$ & $0.89 \pm 0.00$ \\
\hline & 18 & $2.75 \pm 0.02$ & $2.44 \pm 0.02$ & $0.21 \pm 0.00$ & $0.37 \pm 0.00$ \\
\hline & 24 & $1.76 \pm 0.02$ & $2.01 \pm 0.02$ & $0.11 \pm 0.00$ & $0.15 \pm 0.00$ \\
\hline \multirow{5}{*}{$\begin{array}{l}\text { Cyanidin } \\
\text { 3-O-sambubioside-5-rhamnoside }\end{array}$} & 0 & $2.21 \pm 0.02$ & $2.70 \pm 0.00$ & $2.54 \pm 0.01$ & $2.85 \pm 0.04$ \\
\hline & 6 & $2.33 \pm 0.02$ & $2.31 \pm 0.03$ & $0.87 \pm 0.00$ & $1.33 \pm 0.01$ \\
\hline & 12 & $1.60 \pm 0.02$ & $2.54 \pm 0.03$ & $0.38 \pm 0.00$ & $0.59 \pm 0.01$ \\
\hline & 18 & $1.73 \pm 0.02$ & $1.46 \pm 0.01$ & $\operatorname{tr}$ & $0.31 \pm 0.00$ \\
\hline & 24 & $1.18 \pm 0.01$ & $1.21 \pm 0.01$ & $\operatorname{tr}$ & $\operatorname{tr}$ \\
\hline \multirow{5}{*}{ Cyanidin 3-O-rutinoside } & 0 & $55.55 \pm 0.05$ & $58.62 \pm 0.60$ & $54.97 \pm 0.13$ & $58.58 \pm 0.31$ \\
\hline & 6 & $44.24 \pm 0.33$ & $48.64 \pm 0.43$ & $21.75 \pm 0.01$ & $26.15 \pm 0.30$ \\
\hline & 12 & $33.87 \pm 0.29$ & $40.34 \pm 0.47$ & $10.3 \pm 0.11$ & $13.52 \pm 0.17$ \\
\hline & 18 & $25.38 \pm 0.13$ & $26.29 \pm 0.18$ & $4.95 \pm 0.00$ & $5.70 \pm 0.03$ \\
\hline & 24 & $20.49 \pm 0.13$ & $22.66 \pm 0.12$ & $2.95 \pm 0.02$ & $3.19 \pm 0.02$ \\
\hline \multirow{5}{*}{ Sum of anthocyanins } & 0 & $217.28 \pm 0.74$ & $230.84 \pm 2.32$ & $216.85 \pm 2.64$ & $230.33 \pm 1.50$ \\
\hline & 6 & $180.00 \pm 1.99$ & $198.01 \pm 0.20$ & $96.72 \pm 0.23$ & $115.07 \pm 0.41$ \\
\hline & 12 & $143.81 \pm 0.63$ & $167.46 \pm 1.66$ & $50.20 \pm 0.09$ & $63.61 \pm 0.68$ \\
\hline & 18 & $103.26 \pm 0.38$ & $101.42 \pm 1.35$ & $23.93 \pm 0.07$ & $24.68 \pm 0.18$ \\
\hline & 24 & $86.48 \pm 0.54$ & $90.19 \pm 0.78$ & $15.05 \pm 0.14$ & $14.88 \pm 0.07$ \\
\hline
\end{tabular}

${ }^{1}$ Values are expressed as the mean $(n=3) \pm$ standard deviation, tr-traces.

The proportions of the main anthocyanins-cyanidin 3-O-glucoside-rutinoside and cyanidin $3-O$-rutinoside-were $62.2 \%$ and $25.6 \%$ of total anthocyanin content respectively before storage and $66.0 \%$ and $21.4 \%$ after storage at $30{ }^{\circ} \mathrm{C}$. It means that cyanidin 3-glucoside-rutinoside (three sugar moieties) was more stable than cyanidin 3-rutinoside (two sugars). It is in agreement with literature data, indicating that the sugar moiety stabilizes anthocyanin stability [11,20-22].

During the first 12 weeks of storage the anthocyanin content was higher in samples with sugar added, but later the content of anthocyanins decreased faster in these liqueurs, and at the end of the experiment a slightly lower content of them was determined. This can be explained by the fact that presence of anthocyanin degradation products results in more rapid degradation [23,24]. The calculated half-life of total anthocyanins and the parameters of degradation kinetics are presented in Table 5. 
Table 5. Changes of polymeric anthocyanin percentage and the parameters of degradation kinetics of sour cherry liqueurs during storage.

\begin{tabular}{cccccc}
\hline & Week & \multicolumn{2}{c}{ Temperature $\mathbf{1 5}{ }^{\circ} \mathbf{C}$} & \multicolumn{2}{c}{ Temperature $\mathbf{3 0}{ }^{\circ} \mathbf{C}$} \\
\cline { 3 - 6 } & & $\begin{array}{c}\text { Without Sugar } \\
\text { Added }\end{array}$ & $\begin{array}{c}\text { With Sugar } \\
\text { Added }\end{array}$ & $\begin{array}{c}\text { Without Sugar } \\
\text { Added }\end{array}$ & $\begin{array}{c}\text { With Sugar } \\
\text { Added }\end{array}$ \\
\hline Polymeric & 0 & 9.5 & 8.9 & 9.3 & 9.2 \\
anthocyanin & 8 & 12.6 & 10.7 & 20.5 & 18.5 \\
percentage & 16 & 22.7 & 20.7 & 57.5 & 42 \\
\hline $\mathrm{k}(1 /$ week $)$ & 24 & 25.8 & 21.9 & 75.8 & 65.3 \\
$\mathrm{t}_{1 / 2}$ (week) & 0.042 & 0.048 & 0.105 & 0.118 \\
$\mathrm{R}^{2}$ & 16.4 & 14.5 & 6.6 & 5.9 \\
\end{tabular}

Samples without added sugar degraded a little slower than samples with added sugar, the half time being about $12 \%$ shorter in samples with sugar added. More important was the temperature of storage. At $30{ }^{\circ} \mathrm{C}$ anthocyanins degraded about 2.5 times faster than at $15{ }^{\circ} \mathrm{C}$. The half-lives $\left(\mathrm{t}^{1} / 2\right)$ of the anthocyanins were in agreement with the Hellstrom et al. [23] research on anthocyanins in juices stored at different temperatures and the study by Bonerz et al. [11] on tart cherry juices.

\subsection{Color Changes}

Cherry liqueurs were characterized by a nice red, stable color, which was due to the quite good stability of anthocyanin pigments, especially at $15^{\circ} \mathrm{C}$. The differences among samples after 26 weeks of storage were very small (Figure 1), so we decided to measure the color of liqueurs additionally after one year of storage. Color differences were visually noticeable after the annual storage.
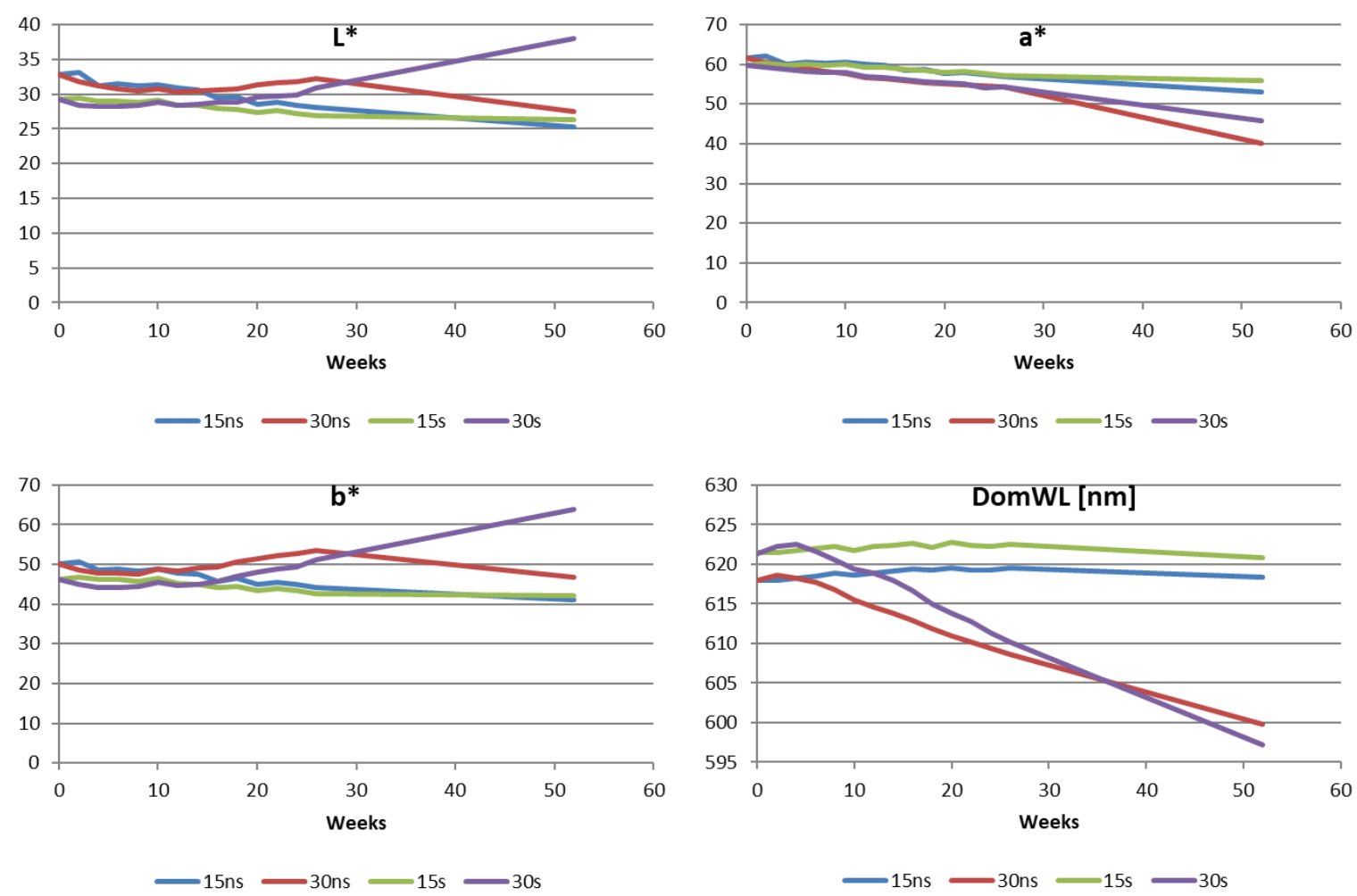

Figure 1. CIELAB chromatic coordinates $L^{*}$ (lightness), $a^{*}$ (red to green), $b^{*}$ (yellow to blue) and DomWL (dominant wavelength) and their changes during storage of liqueurs. 
After 24 weeks of storage, the differences in lightness $\Delta \mathrm{L}^{*}$ were in the range -4.4 to +0.4 units, and after one year of storage the $\Delta \mathrm{L}^{*}$ was between -7.6 and +8.7 , and only the liqueur with sugar, stored at $30{ }^{\circ} \mathrm{C}$, was found to brighten. The red parameter $\left(\mathrm{a}^{*}\right)$ decreased after 24 weeks by $2.2-4.2$ units at $15^{\circ} \mathrm{C}$ and 5.8-7.1 units at $30^{\circ} \mathrm{C}$, and after 52 weeks by 4.0-8.5 and 14.2-21.6 units respectively. Larger changes in this parameter were observed for liqueurs without sugar added. The color parameter $\mathrm{b}^{*}$ (yellowness) increased during storage of liqueurs at $30{ }^{\circ} \mathrm{C}(\Delta \mathrm{a}=2.6 \div 3.0$ units), and decreased at $15^{\circ} \mathrm{C}\left(\Delta \mathrm{a}=2.8 \div 5.3\right.$ units). After one year only in the sample with added sugar stored at $30^{\circ} \mathrm{C}$ was an increase of parameter $\mathrm{b}^{*}$ observed $\left(\Delta \mathrm{b}^{*}=17.4\right)$. Also, the dominant wavelength decreased, but at $15^{\circ} \mathrm{C}$ values were irrelevant $(\triangle \mathrm{DomWL}<1)$, and at $30^{\circ} \mathrm{C}$ the difference compared to initial values was approximately 10 units in the samples stored at $15^{\circ} \mathrm{C}$ and $18-24$ units in the samples stored at $30^{\circ} \mathrm{C}$.

An important parameter is $\Delta \mathrm{E}$, describing the ability of the human eye to discriminate between the colors of products. Pérez-Magariño and González-Sanjosé [25] stated that human eyes can distinguish the color of two samples when $\Delta \mathrm{E}$ is greater than 5 units. Liqueurs' color changed during 24 weeks of storage from $4(15 \mathrm{~s})$ to 8.1 ( $15 \mathrm{~ns})$ units. After one year the total color differences were from 6.4 and 14.7 for $15 \mathrm{~s}$ and $15 \mathrm{~ns}$ to 22.5 and 24.1 for $30 \mathrm{~ns}$ and $30 \mathrm{~s}$ respectively. According to Nikkhah et al. [26] the sugar concentration up to $20 \%$ stabilizes anthocyanins during storage. However, a higher concentration of sugar reduces their stability. Sokót-Łętowska et al. [4] reported that in the production of liqueurs, it is important not to exceed $30 \%$ of sugar in the solution due to unfavorable changes in color. However, temperature of storage is a key factor of the stored product.

Color changes are mainly the result of anthocyanin degradation. Therefore, the anthocyanin polymer percentage was determined in liqueurs Anthocyanin polymer content increased during storage from about $9 \%$ to $22-26 \%$ and $65-76 \%$ at $15{ }^{\circ} \mathrm{C}$ and $30{ }^{\circ} \mathrm{C}$ respectively (Table 5), increasing more in samples without sugar added.

\subsection{Aroma Compounds}

All tested cherry liqueurs had a strong and distinctive aroma. The main component was benzaldehyde, one of the 20 identified substances, representing more than $95 \%$ (Table 6). The cherry stones contain a cyanogenic glycoside, amygdalin, which when subject to enzymatic or thermal degradation releases benzaldehyde [27]. Benzaldehyde possesses a characteristic pleasant almond-like odor and is a desirable flavor attribute of cherry wine and liquors [28]. Small amounts of aromatic benzyl alcohol, benzaldehyde acetals and phenylacetaldehyde were also detected. These data are in agreement with Nikicevic [13]. Diethyl acetal and ethyl esters of benzoic, octanoic or succinic acid present in the liquor were the products of the reaction of the corresponding compounds with ethanol [29]. Small amounts of linear compounds, such as 2-octenal and 1-nonanol, were also detected. The ionones and their aromatic derivatives were also identified. Our results are in agreement with data published by Niu et al. [30] and Sun [31]. They identified a very similar profile of compounds in wine obtained from cherries. The GC-MS profile of aromatic compounds in tested cherry liqueurs indicates that sugar content, temperature and time of maceration had no major impact. The noticeable change, however, of cherry liqueurs' scent may be associated with the formation of the corresponding diethyl acetal.

In organoleptic evaluation all sour cherry liqueur samples were characterized by the typical flavor of sour cherries. Samples stored at $15^{\circ} \mathrm{C}$ were significantly less intense in smell and taste. In samples without sugar, stored at $15^{\circ} \mathrm{C}$, and liqueurs with sugar, stored at $30^{\circ} \mathrm{C}$, there was an acidic "compote" note-not desired in such products. The sample without sugar stored at $30^{\circ} \mathrm{C}$ was evaluated as the worst in terms of both taste and smell. The liqueur made with sugar and stored at $15^{\circ} \mathrm{C}$ had the best flavor. Unfortunately, there was a characteristic bitter almonds note only during the first weeks of storage, maybe because of the short time of alcohol-pits contact during liqueur preparation, which is in agreement with Loch et al. [32]. 
Table 6. Aroma compounds quantified in cherry liqueurs ( $\mu \mathrm{g} / 100 \mathrm{~mL})$.

\begin{tabular}{|c|c|c|c|c|c|c|}
\hline \multirow{2}{*}{ Compounds } & \multirow[b]{2}{*}{$\mathrm{tR}(\min )$} & \multirow[b]{2}{*}{ Week } & \multicolumn{2}{|c|}{ Temperature $15^{\circ} \mathrm{C}$} & \multicolumn{2}{|c|}{ Temperature $30^{\circ} \mathrm{C}$} \\
\hline & & & $\begin{array}{l}\text { Without Sugar } \\
\text { Added }\end{array}$ & $\begin{array}{l}\text { With Sugar } \\
\text { Added }\end{array}$ & $\begin{array}{c}\text { Without Sugar } \\
\text { Added }\end{array}$ & $\begin{array}{l}\text { With Sugar } \\
\text { Added }\end{array}$ \\
\hline \multirow{2}{*}{ Benzaldehyde } & \multirow{2}{*}{6.85} & 6 & $9491.0 \pm 54.76^{1}$ & $10,800.0 \pm 106.30$ & $10,150.0 \pm 44.79$ & $8600.0 \pm 24.32$ \\
\hline & & 24 & $10,900.0 \pm 54.26$ & $11,500.0 \pm 19.52$ & $12,600.0 \pm 51.32$ & $12,600.0 \pm 25.66$ \\
\hline \multirow[b]{2}{*}{ 1-Octanol } & \multirow[b]{2}{*}{8.60} & 6 & $5.0 \pm 0.04$ & $10.0 \pm 0.01$ & $10.0 \pm 0.01$ & $30.0 \pm 0.17$ \\
\hline & & 24 & $30.0 \pm 0.00$ & $40.0 \pm 0.29$ & $20.0 \pm 0.03$ & $60.0 \pm 0.68$ \\
\hline \multirow{2}{*}{ Hexyl acetate } & \multirow{2}{*}{8.67} & 6 & $4.0 \pm 0.01$ & $40.0 \pm 0.34$ & $20.0 \pm 0.04$ & $20.0 \pm 0.17$ \\
\hline & & 24 & $20.0 \pm 0.04$ & $68.0 \pm 0.29$ & $35.0 \pm 0.15$ & $54.0 \pm 0.01$ \\
\hline \multirow{2}{*}{ Benzyl alcohol } & \multirow{2}{*}{9.64} & 6 & $45.0 \pm 0.38$ & $60.0 \pm 0.25$ & $30.0 \pm 0.13$ & $48.0 \pm 0.02$ \\
\hline & & 24 & $78.0 \pm 0.43$ & $47.0 \pm 0.13$ & $35.0 \pm 0.27$ & $47.0 \pm 0.15$ \\
\hline \multirow{2}{*}{ Limonene } & \multirow{2}{*}{10.05} & 6 & $1.0 \pm 0.00$ & $10.0 \pm 0.06$ & $1.0 \pm 0.00$ & $1.0 \pm 0.00$ \\
\hline & & 24 & $1.0 \pm 0.00$ & $1.0 \pm 0.01$ & $1.0 \pm 0.00$ & $1.0 \pm 0.01$ \\
\hline \multirow{2}{*}{ 2-Octenal } & \multirow{2}{*}{10.56} & 6 & $1.0 \pm 0.01$ & $1.0 \pm 0.01$ & $1.0 \pm 0.00$ & $1.0 \pm 0.01$ \\
\hline & & 24 & $1.0 \pm 0.01$ & $1.0 \pm 0.00$ & $1.0 \pm 0.01$ & $1.0 \pm 0.01$ \\
\hline \multirow[b]{2}{*}{ 1-Nonanol } & \multirow[b]{2}{*}{11.55} & 6 & $2.0 \pm 0.00$ & $2.0 \pm 0.02$ & $3.0 \pm 0.00$ & $3.0 \pm 0.02$ \\
\hline & & 24 & $2.0 \pm 0.02$ & $1.0 \pm 0.01$ & $3.0 \pm 0.00$ & $2.0 \pm 0.02$ \\
\hline \multirow{2}{*}{ Unknown } & \multirow{2}{*}{11.97} & 6 & $0.0 \pm 0.00$ & $1.0 \pm 0.00$ & $0.2 \pm 0.00$ & $1.0 \pm 0.01$ \\
\hline & & 24 & $1.0 \pm 0.01$ & $1.0 \pm 0.00$ & $1.0 \pm 0.00$ & $1.0 \pm 0.00$ \\
\hline \multirow{2}{*}{$\begin{array}{c}\text { 2-Nonen-1-ol + } \\
\text { linalool }\end{array}$} & \multirow{2}{*}{12.68} & 6 & $26.0 \pm 0.12$ & $36.0 \pm 0.29$ & $26.0 \pm 0.12$ & $48.0 \pm 0.08$ \\
\hline & & 24 & $26.0 \pm 0.11$ & $78.0 \pm 0.04$ & $48.0 \pm 0.46$ & $68.0 \pm 0.38$ \\
\hline \multirow{2}{*}{ Ethyl benzoate } & & 6 & $55.0 \pm 0.44$ & $95.0 \pm 0.05$ & $73.0 \pm 0.22$ & $87.0 \pm 0.28$ \\
\hline & 15.25 & 24 & $45.0 \pm 0.20$ & $68.0 \pm 0.41$ & $28.0 \pm 0.18$ & $78.0 \pm 0.64$ \\
\hline Diethyl succinate & & 6 & $34.0 \pm 0.38$ & $69.0 \pm 0.30$ & $48.0 \pm 0.03$ & $89.0 \pm 0.36$ \\
\hline Diethyl succinate & 15.66 & 24 & $68.0 \pm 0.61$ & $45.0 \pm 0.25$ & $65.0 \pm 0.63$ & $67.0 \pm 0.27$ \\
\hline Octanoic acid ethyl & & 6 & $7.0 \pm 0.01$ & $8.0 \pm 0.07$ & $9.0 \pm 0.02$ & $87.0 \pm 0.79$ \\
\hline ester & 17.02 & 24 & $48.0 \pm 0.30$ & $68.0 \pm 0.74$ & $59.0 \pm 0.18$ & $71.0 \pm 0.44$ \\
\hline Ethyl acetal of & & 6 & $23.0 \pm 0.20$ & $160.0 \pm 1.18$ & $120.0 \pm 1.34$ & $140.0 \pm 0.19$ \\
\hline benzaldehyde & 18.13 & 24 & $980.0 \pm 5.99$ & $680.0 \pm 3.54$ & $780.0 \pm 3.09$ & $470.0 \pm 2.34$ \\
\hline & & 6 & $17.0 \pm 0.08$ & $580.0 \pm 1.38$ & $80.0 \pm 0.33$ & $180.0 \pm 1.91$ \\
\hline Diethyl malate & 19.41 & 24 & $150.0 \pm 0.63$ & $950.0 \pm 3.87$ & $870.0 \pm 5.32$ & $680.0 \pm 2.69$ \\
\hline Phenylacetalde-hyde & 2024 & 6 & $6.0 \pm 0.03$ & $9.0 \pm 0.08$ & $9.0 \pm 0.05$ & $3.0 \pm 0.03$ \\
\hline diethyl acetal & 22.24 & 24 & $24.0 \pm 0.04$ & $48.0 \pm 0.30$ & $35.0 \pm 0.07$ & $78.0 \pm 0.19$ \\
\hline Methyldecanoate & & 6 & $20.0 \pm 0.17$ & $53.0 \pm 0.40$ & $35.0 \pm 0.18$ & $47.0 \pm 0.04$ \\
\hline Methyl decanoate & 22.55 & 24 & $24.0 \pm 0.03$ & $48.0 \pm 0.22$ & $26.0 \pm 0.10$ & $87.0 \pm 0.34$ \\
\hline & & 6 & $2.0 \pm 0.01$ & $78.0 \pm 0.68$ & $6.0 \pm 0.03$ & $59.0 \pm 0.24$ \\
\hline ar-lonone & 23.480 & 24 & $20.0 \pm 0.13$ & $45.0 \pm 0.26$ & $65.0 \pm 0.24$ & $70.0 \pm 0.73$ \\
\hline & & 6 & $4.0 \pm 0.02$ & $48.0 \pm 0.29$ & $3.0 \pm 0.02$ & $45.0 \pm 0.50$ \\
\hline Ethyl decanoate & 24.593 & 24 & $520.0 \pm 4.71$ & $68.0 \pm 0.55$ & $41.0 \pm 0.20$ & $78.0 \pm 0.60$ \\
\hline & & 6 & $5.0 \pm 0.02$ & $7.0 \pm 0.07$ & $9.0 \pm 0.09$ & $5.0 \pm 0.02$ \\
\hline$\alpha$-Ionone & 24.954 & 24 & $48.0 \pm 0.51$ & $48.0 \pm 0.47$ & $65.0 \pm 0.05$ & $36.0 \pm 0.33$ \\
\hline B_Jonone & & 6 & $9.0 \pm 0.07$ & $7.0 \pm 0.00$ & $7.0 \pm 0.00$ & $5.0 \pm 0.04$ \\
\hline$\beta$-lonone & 25.749 & 24 & $40.0 \pm 0.27$ & $50.0 \pm 0.50$ & $650.0 \pm 6.03$ & $98.0 \pm 0.01$ \\
\hline & & 6 & $9760.0 \pm 59.6$ & $12070.0 \pm 12.3$ & $10640.0 \pm 78.3$ & $9500.0 \pm 55.9$ \\
\hline Total & & 24 & $13030.0 \pm 147.4$ & $13860.0 \pm 142.7$ & $15430.0 \pm 117.0$ & $14650.0 \pm 54.7$ \\
\hline
\end{tabular}

${ }^{1}$ Values are expressed as the mean $(n=3) \pm$ standard deviation.

\subsection{Changes in Antioxidant Activity}

Antioxidant activity of liqueurs was measured by two methods: ABTS and by determination of substances which react with Folin-Ciocalteu reagent (FC) (Table 7). 
Table 7. Changes in substances reacting with Folin-Ciocalteu reagent (FC) content and antioxidant activity ABTS, of sour cherry liqueurs during 24 weeks storage in temperatures $15^{\circ} \mathrm{C}$ and $30^{\circ} \mathrm{C}$.

\begin{tabular}{|c|c|c|c|c|c|}
\hline \multirow[b]{2}{*}{ Test } & \multirow[b]{2}{*}{ Week } & \multicolumn{2}{|c|}{ Temperature $15^{\circ} \mathrm{C}$} & \multicolumn{2}{|c|}{ Temperature $30^{\circ} \mathrm{C}$} \\
\hline & & $\begin{array}{c}\text { Without Sugar } \\
\text { Added }\end{array}$ & $\begin{array}{l}\text { With Sugar } \\
\text { Added }\end{array}$ & $\begin{array}{c}\text { Without Sugar } \\
\text { Added }\end{array}$ & $\begin{array}{c}\text { With Sugar } \\
\text { Added }\end{array}$ \\
\hline \multirow{5}{*}{$\mathrm{FC}(\mathrm{mg} \mathrm{GAE} / \mathrm{mL})$} & 0 & $1.16 \pm 0.04^{1}$ & $1.16 \pm 0.02$ & $1.13 \pm 0.01$ & $1.15 \pm 0.07$ \\
\hline & 6 & $1.15 \pm 0.01$ & $1.16 \pm 0.06$ & $1.12 \pm 004$ & $1.15 \pm 0.01$ \\
\hline & 12 & $1.19 \pm 0.04$ & $1.18 \pm 0.05$ & $1.06 \pm 0.06$ & $1.18 \pm 0.04$ \\
\hline & 18 & $1.21 \pm 0.04$ & $1.10 \pm 0.03$ & $0.98 \pm 0.02$ & $1.21 \pm 0.03$ \\
\hline & 24 & $1.10 \pm 0.03$ & $1.21 \pm 0.05$ & $1.14 \pm 0.01$ & $1.25 \pm 0.05$ \\
\hline \multirow{5}{*}{$\operatorname{ABTS}(\mu \mathrm{M} \mathrm{TE} / \mathrm{mL})$} & 0 & $11.56 \pm 0.29$ & $11.77 \pm 0.14$ & $12.28 \pm 0.64$ & $12.62 \pm 0.47$ \\
\hline & 6 & $11.56 \pm 0.70$ & $11.86 \pm 0.23$ & $11.46 \pm 0.71$ & $10.83 \pm 0.61$ \\
\hline & 12 & $11.67 \pm 0.28$ & $11.30 \pm 0.22$ & $10.64 \pm 0.38$ & $8.66 \pm 0.43$ \\
\hline & 18 & $11.51 \pm 0.18$ & $10.74 \pm 0.39$ & $9.47 \pm 0.05$ & $8.78 \pm 0.07$ \\
\hline & 24 & $10.83 \pm 0.29$ & $10.68 \pm 0.48$ & $9.90 \pm 0.32$ & $7.85 \pm 0.19$ \\
\hline
\end{tabular}

${ }^{1}$ Values are expressed as the mean $(n=3) \pm$ standard deviation.

During 24 weeks of storage only small changes in antioxidant activity were observed. Total phenolic content before storage was at the level of $1.15 \mathrm{mg}$ GAE/mL and 1.10-1.14 or 1.21-1.25 $\mu \mathrm{g}$ GAE/mL after storage in samples without and with sugar respectively. Our results are in agreement with other authors. Heinonen et al. [33] showed that cherry liqueurs contain about $1.08 \mathrm{mg}$ of gallic acid equivalents in $1 \mathrm{~mL}$, while Rødtjer et al. [14] determined $1.52 \mathrm{mg} \mathrm{GAE} / \mathrm{mL}$. Transformations of anthocyanins and other liqueur components during storage lead to polymerization and formation of new molecules that can react with Folin-Ciocalteu reagent.

Piljac-Žegarac et al. [34] studied fluctuations of phenolic compound content and antioxidant capacity during storage of fruit juices and found that all analyzed fruit juices exhibited substantial fluctuations in the FC content and antioxidant capacity during 29-day storage. Fluctuations in the content of polyphenolic compounds during storage of liqueurs of myrtle were also observed by Montoro et al. [35]. Kallithraka et al. [19] found an increase in the content of phenolic compounds after 9 months of storage of white wines as compared to 3 and 6 months. Klimczak et al. [36] found an increase of polyphenols in citrus juices after 6 months of storage.

The antioxidant activity of cherry liqueurs measured by the ABTS test changed during storage. Average antioxidant activity before storage was 11.6-12.6 $\mu \mathrm{M}$ TE/1 mL (ABTS) and after storage it decreased by $6.4-9.2 \%$ in samples stored at $15{ }^{\circ} \mathrm{C}$ and by $19.4-37.8 \%$ in samples stored at $30{ }^{\circ} \mathrm{C}$, decreasing more in liqueurs with added sugar. A similar effect was observed by Montoro et al. [35] in myrtle liqueurs, and was explained by hydrolysis of the flavonoid glycosides, which give an additional hydroxyl group which can participate in the reaction with the ABTS cation radical. Antioxidant activity fluctuations were observed by Sokól-Łętowska et al. during storage of sour cherry liqueurs made with different amounts of sugar [4]. The high antioxidant activity is in agreement with the high content of phenolic compounds in berries. Correlation coefficients $\left(\mathrm{R}^{2}\right)$ of ABTS and phenolic compounds were 0.80 (flavan-3-ols), 0.78 (phenolic acids), 0.91 (flavonols) and 0.85 (anthocyanins).

\subsection{Principal Component Analysis}

Principal component analysis (PCA) was conducted to confirm some relationships among analyzed variables. PCA was performed using Statistica 13.1 software on mean values of 20 samples (liqueurs stored for $0,6,12,18$ and 24 weeks with and without sugar at $15{ }^{\circ} \mathrm{C}$ and $30^{\circ} \mathrm{C}$ ) and 19 variables (phenolic components, color attributes and antioxidant activity) for detecting the most important factors of variability and to describe the relationship between variables and observations. The first principal component (PC1) accounted for $63,98 \%$ of the variability in the data set. The second principal component accounted for $17.67 \%$ of the variance in the data set. The sum of $81.65 \%$ is high enough for a good presentation of multidimensional space in the two-dimensional projection. 
The loading plot PC2 versus PC1 (Figure 2) shows a good clustering of the objects according to the groups defined (components, color attributes and antioxidant activity) although not all groups are completely separated. On the right side of the plot are phenolic compounds. It indicating that all are very similar. Only one variable referred to quercetin lays in the left side. Quercetin appears probably as a result of the decomposition of quercetin derivatives in stored liqueurs. Antioxidant activity (ABTS) is correlated with phenolic compounds. Color Parameter $\mathrm{a}^{*}$ is located near phenolic compound cluster as redness od liqueurs is strongly connected with anthocyanin content. Color attributes: $b^{*}, L^{*}$ and DWL are associated with PC2 and these variables are almost not correlated with phenolic composition of liqueurs. The FC variable (substances reacting with Folin-Ciocalteu reagent) is not good parameter for estimation of polyphenol changes during storage.

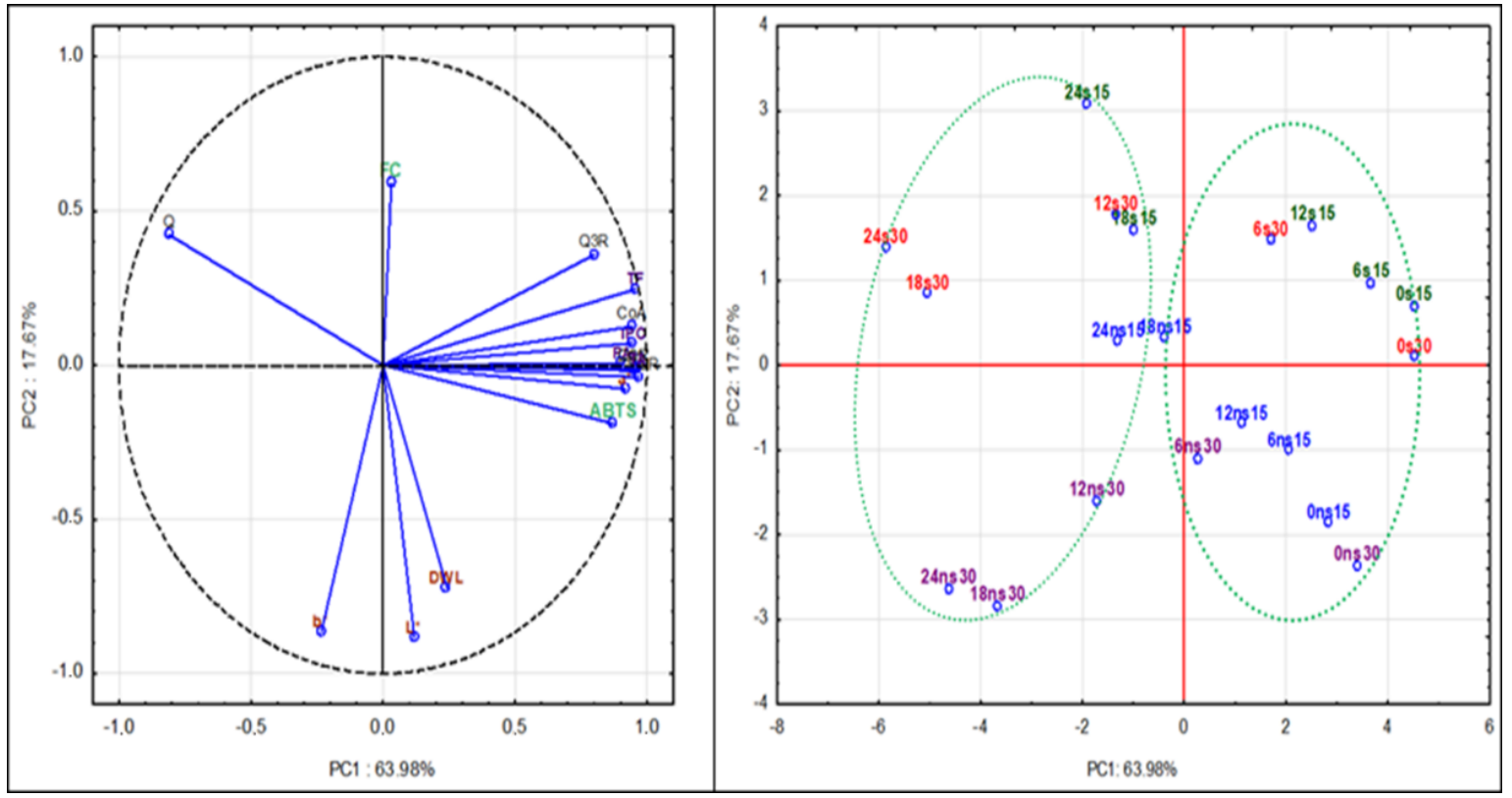

Figure 2. Principal Component Analysis (PCA) loadings plot and score plot of major components, color attributes and antioxidant activity of cherry liqueurs with (s) and without sugar (ns) stored at $15^{\circ} \mathrm{C}(15)$ and $30{ }^{\circ} \mathrm{C}(30)$ during 24 weeks $(0,6,12,18,24)$.

Liqueurs samples prepared with and without sugar and at different temperatures can be distinguished in the scores plot. Storage longer than 12 weeks negatively correlated with antioxidant activity and phenolic compound contents. In addition, the early, and late stages of the storage can be distinguished as indicated by the green lines. Liqueurs with sugar are well separated, by being on positive region of $\mathrm{PC} 2$, from liqueurs without sugar laying on negative region of PC2.

\section{Materials and Methods}

\subsection{Preparation of Liqueurs}

The sour cherries used to produce liqueurs were purchased from local market retailers and stored at $-20^{\circ} \mathrm{C}$ before preparation of liqueurs. The fruit $(2 \mathrm{~kg})$ was soaked in glass jars with the same mass of ethanol (65\% vol.). Process was carried out at room temperature for three weeks without light. The contents of the jars were stirred gently every day. After 3 weeks of maceration, the fruit extract was separated from the fruit and divided into two parts. To one of them sugar was added in the amount of $1 / 4$ of the extract mass, and to the other one the same mass of water. After the dissolution of sugar each liqueur was divided into two parts and stored at temperatures of $15^{\circ} \mathrm{C}$ and $30^{\circ} \mathrm{C}$ for 6 months. The liqueurs prepared with sugar were labeled $15 \mathrm{~s}$ and $30 \mathrm{~s}$, and those without sugar-15 ns and 
$30 \mathrm{~ns}$-according to the storage temperature of $15^{\circ} \mathrm{C}$ and $30^{\circ} \mathrm{C}$. The experiment was carried out in two technological duplicates.

\subsection{Identification of Phenolic Compounds by LC-MS Method}

Identification of compounds was performed on an ultra-performance liquid chromatography (Acquity UPLC System) connected to a quadrupole time of flight (Q-TOF) MS instrument (UPLC/Synapt Q-TOF MS, Waters Corp., Milford, MA, USA) equipped with an electrospray ionization (ESI) source. Separation was achieved on the Acquity BEH C18 column $(100 \mathrm{~mm} \times 2.1 \mathrm{~mm}$ i.d., $1.7 \mu \mathrm{m}$; Waters, Milford, MA, USA). 4.5\% formic acid in water was used as the eluent A and acetonitrile as eluent B. The gradient program was as follows: $0 \mathrm{~min}-99 \%$ (A), $12 \mathrm{~min}-75 \%$ (A), $12.5 \mathrm{~min}-100 \%$ (B), $13.5 \mathrm{~min}-99 \%$ (A). The flow rate was $0.45 \mathrm{~cm}^{3} / \mathrm{min}$ and the injection volume was $5 \mu \mathrm{L}$. The column temperature was $30^{\circ} \mathrm{C}$. The major the Q-TOF MS operating parameters were: capillary voltage, $3.0 \mathrm{kV}$; cone voltage, $40 \mathrm{~V}$; cone gas flow of $11 \mathrm{~L} / \mathrm{h}$; collision energy, $50 \mathrm{eV}$; source temperature, $100{ }^{\circ} \mathrm{C}$; desolvation temperature, $250^{\circ} \mathrm{C}$; collision gas, argon; desolvation gas (nitrogen) flow rate, $600 \mathrm{~L} / \mathrm{h}$; data acquisition range, $m / z$ 100-1500 Da; ionization mode, negative. The data were collected by Mass-Lynx v. 4.1. software (Waters, Milford, MA, USA) [16].

\subsection{Quantitative Analysis of Phenolic Compounds by HPLC Method}

The contents of anthocyanins (TA), phenolic acids (PA), procyanidins and flavan-3-ols (TPC), flavonols (TF), and their derivatives were calculated on the basis of HPLC-PDA assays as described previously by Sokół-Łẹtowska et al. [15]. Phenolic compounds were monitored at $320 \mathrm{~nm}$ for hydroxycinnamic acids, $360 \mathrm{~nm}$ for flavonols, $280 \mathrm{~nm}$ for flavanols and $520 \mathrm{~nm}$ for anthocyanins. The content of anthocyanins, flavonols, flavanols, and hydroxycinnamic acids were calculated based on calibration curves determined experimentally the content of anthocyanins was converted into cyanidin 3-O-glucoside, flavonols into quercetin 3-rutinoside, flavanols into (+) catechin and hydroxycinnamic acids into chlorogenic acid. Analyses were performed in three repetitions. The results were expressed as $\mu \mathrm{g} / \mathrm{mL}$.

The calibration curves were obtained by the external standard method on six levels of concentration of standard compounds (cyanidin 3-O glucoside-Extrasynthese, Lyon Nord, France, quercetin 3-O rutinoside, $(+)$ catechin and chlorogenic acid-Sigma Aldrich, Steinheim, Germany), with three injections per level (Table 8 ). Chromatogram peak areas were plotted against the known concentrations of the standard solutions. Linear regression equations were calculated by the least squares method. As the regression coefficients $R^{2}$ were $\geq 0.995$, the relations were considered linear, and thus acceptable for quantifying the compounds.

Table 8. Analytical characteristics for determination of phenolic compounds.

\begin{tabular}{cccccc}
\hline Compound & $\begin{array}{c}\text { Linear Range } \\
(\mu \mathrm{g} / \mathbf{m L})\end{array}$ & $\begin{array}{c}\text { Equation of } \\
\text { Calibration }\end{array}$ & $\begin{array}{c}\text { Correlation } \\
\text { Coefficient } \\
\boldsymbol{R}^{2}\end{array}$ & $\begin{array}{c}\text { LOD } \\
(\mu \mathrm{g} / \mathrm{mL})\end{array}$ & $\begin{array}{c}\text { LOQ } \\
(\boldsymbol{\mu g} / \mathbf{m L})\end{array}$ \\
\hline Cyanidin 3-O-glucoside & $10-75$ & $y=0.8538 x$ & 0.9994 & 0.073 & 0.241 \\
Quercetin 3-O-rutinoside & $20-300$ & $y=1.9793 x$ & 0.9961 & 0.107 & 0.354 \\
$(+)$ Catechin & $20-200$ & $y=4.1786 x$ & 0.9996 & 0.438 & 1.446 \\
Chlorogenic acid & $20-300$ & $y=0.9195 x$ & 0.9998 & 0.062 & 0.199 \\
\hline
\end{tabular}

$y$-concentration, $x$-area.

RSD values of HPLC method were $0.36-7.14$ for interday and intraday. Recovery values were 98.10-105.94\% (Table S3). It shows, that method was reproducible and accurate. 


\subsection{Determination of Antioxidant Activity}

The antioxidant activity of cherry liqueurs was determined using the Trolox equivalent antioxidant capacity (TEAC) with ABTS cation radical and was carried out according to Re et al. [37], TEAC results are expressed as $\mu \mathrm{M}$ of Trolox equivalents (TE) per $1 \mathrm{~mL}$ of liqueur. Content of substances which react with the Folin-Ciocalteu reagent (FC) were determined by the Folin-Ciocalteu method using gallic acid (GA) as a standard for the calibration curve. The results of the assay were calculated and expressed as milligrams of GA equivalent (GAE) per $1 \mathrm{~mL}$ of liqueur. The data were read at spectrophotometer (Shimadzu UV-2401 PC, Kyoto, Japan). Data are reported as the mean of three measurements.

\subsection{Anthocyanins Polymers}

Polymerized anthocyanin determination was performed with the sodium bisulfite method according to Wrolstad [38]. The results of the assay were calculated and expressed as percent of polymeric anthocyanins.

\subsection{GC/MS Analysis}

The chemical composition of the volatile compounds was performed according to the procedure described by Tešević [39]. Briefly, liquors $(80 \mathrm{~mL})$ were mixed with ultrapure water $(100 \mathrm{~mL})$ containing sodium chloride $(4 \mathrm{~g})$ and then with dichloromethane $(50 \mathrm{~mL})$. 2-Undecanone $(1 \mu \mathrm{L})$ was added as an internal standard for semi-quantification. Next, the mixture was stirred for 30 min using a magnetic stirrer. The layers were separated, and the organic layer was dried ( $2 \mathrm{~h}$ ) over anhydrous sodium sulfate. The extract was concentrated to $1.0 \mathrm{~mL}$ under a gentle stream of nitrogen and kept at $-27^{\circ} \mathrm{C}$ in vials until the analysis. Identification and quantification of compounds present in the liqueurs were performed using gas chromatography (GC, Chrompack CP-3380 with FID detection, Varian, Walnut Creek, CA, USA) and gas chromatography/mass spectrometry (GC/MS) (Chrompack Saturn 2000, Varian, Wallnut Creek, CA, USA) with a a TRACE TR-5 column (5\% phenyl methylpolysiloxane, $30 \mathrm{~m} \times 0.53 \mathrm{~mm}$ i.d., $0.25 \mu \mathrm{m}$ film, Thermo Fisher Scientific, Waltham, MA, USA). Scanning was performed at 1 scan s$^{-1}$ from m/z 39 to 400 in the electron impact (EI) mode at $70 \mathrm{eV}$. helium was used as the carrier gas at a flow rate of $1 \mathrm{~mL} \mathrm{~min}^{-1}$ in a split ratio of 1:20 and the following temperature program: rate of $5{ }^{\circ} \mathrm{C} \mathrm{min}^{-1}$ from 80 to $200{ }^{\circ} \mathrm{C}$; rate of $25^{\circ} \mathrm{C} \mathrm{min}{ }^{-1}$ from 200 to $280{ }^{\circ} \mathrm{C}$; final hold at $280^{\circ} \mathrm{C}$ for $5 \mathrm{~min}$. The injector and detector were kept at 200 and $300^{\circ} \mathrm{C}$ respectively. Most compounds were identified by means of three methods: (1) Kováts indices; (2) GC/MS retention times (authentic standards); (3) mass spectra with similarity indices $>90 \%$ (NIST Mass Spectral Search Program Version 2.0d, Gaithersburg, MD, USA).

\subsection{Color}

The color of the liqueurs was determined with an on-camera instrumental method on the ColorQuest (HunterLab, Reston, VA, USA) apparatus, on the L*a*b* scale, D65 illuminant and observer $10^{\circ}$, transmitted light. Color of cherry liqueurs was additionally measured after one year of storage.

\subsection{Organoleptic Evaluation}

Organoleptic analyses were carried out by a team of five trained tasters, always the same persons to assess flavor and taste.

\subsection{Kinetics}

Degradation kinetics of main phenolic compounds during storage are obtained by determining the rate constants $(k)$ at a given temperature against the time and half-life $\left(t_{1 / 2}\right)$. Degradation of 
phenolic compounds was considered as first-order reaction. The parameters of degradation kinetics were calculated using the following equations:

$$
\begin{aligned}
\mathrm{k} & =\frac{1}{\mathrm{t}} \ln \left(\frac{\mathrm{c}_{0}}{\mathrm{c}_{t}}\right) \\
\mathrm{t}_{1 / 2} & =\frac{-\ln (0,5)}{\mathrm{k}},
\end{aligned}
$$

where $c_{t}$ is the compound concentration $(\mu \mathrm{g} / \mathrm{mL})$ at time $\mathrm{t}(\mathrm{min}), \mathrm{c}_{0}$ is the initial concentration $(\mathrm{t}=0)$, $\mathrm{k}$ is the reaction rate constant.

\subsection{Statistical Analysis}

Correlation analysis and principal component analysis (PCA) was performed using Statistica (data analysis software system), version 13.1 (StatSoft, Tulsa, OK, USA) on mean values of 20 samples (liqueurs stored for $0,6,12,18$ and 24 weeks with and without sugar at $15^{\circ} \mathrm{C}$ and $30^{\circ} \mathrm{C}$ ) and 19 variables: time (w0, w6, w12, w18, w24), temperature of storage (t15, t30), sugar addition (s, ns), antioxidant activity (ABTS), substances reacting with the Folin-Ciocalteu reagent (FC), procyanidin B2 (B2) and total procyanidins and flavan-3-ols (TPC), quercetin 3-rutinoside (Q3R), quercetin (Q), total flavonols (FL), coumaroylquinic acid (CoQA) and total phenolic acids (PA), cyanidin 3-O-glucosyl-rutinoside (C3RG), cyanidin 3-O-rutinoside (C3R) and total anthocyanins (AN), lightness $\left(\mathrm{L}^{*}\right)$, redness $\left(\mathrm{a}^{*}\right)$, yellowness $\left(\mathrm{b}^{*}\right)$ and dominant wavelength (DWL).

\section{Conclusions}

This study is a contribution to knowledge about the phenolic compounds and antioxidant activity changes of sour cherry liqueurs. Their antiradical activity against ABTS is strongly correlated with the contents of flavonols, anthocyanins, flavanols and phenolic acids. Studies after a half-year liqueur storage period showed that their characteristic features are almost unchanged if stored at $15^{\circ} \mathrm{C}$ and without added sugar, but organoleptic properties were better in samples stored at $30^{\circ} \mathrm{C}$. It is best to make a cherry liqueur with no added sugar and store it at $15^{\circ} \mathrm{C}$. This gives the product a good color and a high content of active compounds. Long-term (i.e., longer than half a year) storage and sugar addition reduce the color attributes but increase the organoleptic value without a great influence on antioxidant activity. Our results suggest that it might be interesting to study other technological variables of the production process, as well as different varieties of cherries.

Supplementary Materials: The supplementary materials are available online. Figure S1: LC MS/MS chromatogram of of phenolic compounds in sour cherry liqueurs in positive (A) and negative mode (B), Table S1: LC-MS identification of phenolic compounds in sour cherry liqueurs, Table S2: Chromatographic data for phenolic compounds of cherry liqueurs, Table S3: Validation-intra-day and inter-day precision.

Author Contributions: A.S.-Ł., A.Z.K., A.S. and A.N.-O. conceived, designed, and performed the experiments and wrote the paper. A.S.-E., A.Z.K., A.S., K.W and A.N.-O. analyzed and interpreted the experimental results. All authors read and approved the final manuscript.

Funding: This study was supported by the Polish Ministry of Science and Higher Education under Grant No. N N312 399239.

Acknowledgments: Project supported by Wroclaw Centre of Biotechnology, programme The Leading National Research Centre (KNOW) for years 2014-2018.

Conflicts of Interest: The authors declare no conflict of interest.

\section{References}

1. Alamprese, C.; Pompei, C. Influence of processing variables on some characteristics of Nocino liqueur. Food Chem. 2005, 92, 203-209. [CrossRef] 
2. Egea, T.; Adele Signorini, M.; Bruschi, P.; Rivera, D.; Obon, C.; Alcaraz, F.; Antonio Palazon, J. Spirits and liqueurs in European traditional medicine: Their history and ethnobotany in Tuscany and Bologna (Italy). J. Ethnopharmacol. 2015, 175, 241-255. [CrossRef] [PubMed]

3. Kucharska, A.Z.; Sokół-Łętowska, A.; Hudko, J.; Nawirska-Olszańska, A. Influence of the preparation procedure on the antioxidant activity and color of liqueurs from cornelian cherry (Cornus mas 1.). Pol. J. Food Nutr. Sci. 2007, 57, 343-347.

4. Sokół-Łętowska, A.; Kucharska, A.Z.; Nawirska-Olszańska, A. Wpływ dodatku cukru na jakość nalewek wiśniowych podczas przechowywania. Zesz. Nauk. UEP 2011, 205, 126-134.

5. U.S. Department of Health and Human Services; U.S. Department of Agriculture (Eds.) 2010-2015 Dietary Guidelines for Americans, 7th ed.; U.S. Government Printing Office: Washington, WA, USA, 2010.

6. U.S. Department of Health and Human Services; U.S. Department of Agriculture (Eds.) 2015-2020 Dietary Guidelines for Americans, 8th ed.; U.S. Government Printing Office: Washington, WA, USA, 2015. Available online: https: / health.gov/dietaryguidelines/2015/guidelines / (accessed on 10 July 2018).

7. De Lorimier, A.A. Alcohol, wine, and health. Am. J. Surg. 2000, 180, 357-361. [CrossRef]

8. Alrgei, H.O.S.; Dabić, D.Č.; Natić, M.M.; Rakonjac, V.S.; Milojković-Opsenica, D.; Tešić, Ž.L.; Fotirić Akšić, M.M. Chemical profile of major taste- and health-related compounds of Oblačinska sour cherry. J. Sci. Food Agric. 2015, 96, 1241-1251. [CrossRef] [PubMed]

9. Burkhardt, S.; Tan, D.X.; Manchester, L.C.; Hardeland, R.; Reiter, R.J. Detection and quantification of the antioxidant melatonin in Montmorency and Balaton tart cherries (Prunus cerasus). J. Agric. Food Chem. 2001, 49, 4898-4902. [CrossRef] [PubMed]

10. Cao, J.; Jiang, Q.; Lin, J.; Li, X.; Sun, C.; Chen, K. Physicochemical characterisation of four cherry species (Prunus spp.) grown in China. Food Chem. 2015, 173, 855-863. [CrossRef] [PubMed]

11. Bonerz, D.; Würth, K.; Dietrich, H.; Will, F. Analytical characterization and the impact of ageing on anthocyanin composition and degradation in juices from five sour cherry cultivars. Eur. Food Res. Technol. 2007, 224, 355-364. [CrossRef]

12. Sokół-Łętowska, A. Związki fenolowe w nalewkach z wybranych owoców; Wydawnictwo Uniwersytetu Przyrodniczego we Wrocławiu: Wrocław, Poland, 2013; p. 112.

13. Nikićević, N.; Veličković, M.; Jadranin, M.; Vučković, I.; Novaković, M.; Vujisić, L.; Stanković, M.; Urošević, I.; Tešević, V. The effects of the cherry variety on the chemical and sensorial characteristics of cherry brandy. J. Serb. Chem. Soc. 2011, 9, 1219-1228. [CrossRef]

14. Rødtjer, A.; Skibsted, L.; Andersen, M. Identification and quantification of phenolics in aromatic bitter and cherry liqueur by HPLC with electrochemical detection. Eur. Food Res. Technol. 2006, 223, 663-668. [CrossRef]

15. Sokół-Łętowska, A.; Kucharska, A.Z.; Wińska, K.; Szumny, A.; Nawirska-Olszańska, A.; Mizgier, P.; Wyspiańska, D. Composition and antioxidant activity of red fruit liqueurs. Food Chem. 2014, 157, 533-539. [CrossRef] [PubMed]

16. Nowicka, P.; Wojdylo, A. Stability of phenolic compounds, antioxidant activity and colour through natural sweeteners addition during storage of sour cherry puree. Food Chem. 2016, 196, 925-934. [CrossRef] [PubMed]

17. Toydemir, G.; Capanoglu, E.; Gomez Roldan, M.V.; de Vos, R.C.H.; Boyacioglu, D.; Hall, R.D.; Beekwilder, J. Industrial processing effects on phenolic compounds in sour cherry (Prunus cerasus 1.) fruit. Food Res. Int. 2013, 53, 218-225. [CrossRef]

18. Wojdyło, A.; Nowicka, P.; Laskowski, P.; Oszmiański, J. Evaluation of sour cherry (Prunus cerasus 1.) fruits for their polyphenol content, antioxidant properties, and nutritional components. J. Agric. Food Chem. 2014, 62, 12332-12345. [CrossRef] [PubMed]

19. Kallithraka, S.; Salacha, M.I.; Tzourou, I. Changes in phenolic composition and antioxidant activity of white wine during bottle storage: Accelerated browning test versus bottle storage. Food Chem. 2009, 113, 500-505. [CrossRef]

20. Brauch, J.E.; Kroner, M.; Schweiggert, R.M.; Carle, R. Studies into the stability of 3-O-glycosylated and 3,5-O-diglycosylated anthocyanins in differently purified liquid and dried maqui (Aristotelia chilensis (mol.) Stuntz) preparations during storage and thermal treatment. J. Agric. Food Chem. 2015, 63, 8705-8714. [CrossRef] [PubMed]

21. De Rosso, V.V.; Mercadante, A.Z. Evaluation of colour and stability of anthocyanins from tropical fruits in an isotonic soft drink system. Innov. Food Sci. Emerg. Technol. 2007, 8, 347-352. [CrossRef] 
22. Macheix, J.J.; Fleuriet, A.; Billot, J. Fruit Phenolics; CRC Press, Inc.: Boca Raton, FL, USA, 1990; p. 378.

23. Hellström, J.; Mattila, P.; Karjalainen, R. Stability of anthocyanins in berry juices stored at different temperatures. J. Food Compos. Anal. 2013, 31, 12-19. [CrossRef]

24. Patras, A.; Brunton, N.P.; O'Donnell, C.; Tiwari, B.K. Effect of thermal processing on anthocyanin stability in foods; mechanisms and kinetics of degradation. Trends Food Sci. Technol. 2010, 21, 3-11. [CrossRef]

25. Pérez-Magariño, S.; González-Sanjosé, M.L. Application of absorbance values used in wineries for estimating CIELAB parameters in red wines. Food Chem. 2003, 81, 301-306. [CrossRef]

26. Nikkhah, E.; Khayamy, M.; Heidari, R.; Jamee, R. Effect of sugar treatment on stability of anthocyanin pigments in berries. J. Biol. Sci. 2007, 7, 1412-1417.

27. Bolarinwa, I.F.; Orfila, C.; Morgan, M.R.A. Amygdalin content of seeds, kernels and food products commercially-available in the UK. Food Chem. 2014, 152, 133-139. [CrossRef] [PubMed]

28. Wolken, W.A.M.; Tramper, J.; van der Werf, M.J. Amino acid-catalysed retroaldol condensation: The production of natural benzaldehyde and other flavour compounds. Flavour Frag. J. 2004, 19, 115-120. [CrossRef]

29. Shen, Y.F. Study on the formation mechanism of four main kinds of ethyl esters in the fermentation of liquour. Liquor-Making Sci. Technol. 2003, 5, 005.

30. Niu, Y.W.; Zhang, X.M.; Xiao, Z.B.; Song, S.Q.; Eric, K.; Jia, C.S.; Yu, H.Y.; Zhu, J.C. Characterization of odor-active compounds of various cherry wines by gas chromatography-mass spectrometry, gas chromatography-olfactometry and their correlation with sensory attributes. J. Chromatogr. B.-Anal. Technol. Biomed. Life Sci. 2011, 879, 2287-2293. [CrossRef] [PubMed]

31. Sun, S.Y.; Jiang, W.G.; Zhao, Y.P. Comparison of aromatic and phenolic compounds in cherry wines with different cherry cultivars by HS-SPME-GC-MS and HPLC. Int. J. Food Sci. Technol. 2012, 47, 100-106. [CrossRef]

32. Loch, C.; Reusch, H.; Ruge, I.; Godelmann, R.; Pflaum, T.; Kuballa, T.; Schumacher, S.; Lachenmeier, D.W. Benzaldehyde in cherry flavour as a precursor of benzene formation in beverages. Food Chem. 2016, 206, 74-77. [CrossRef] [PubMed]

33. Heinonen, I.M.; Lehtonen, P.J.; Hopia, A.I. Antioxidant activity of berry and fruit wines and liquors. J. Agric. Food Chem. 1998, 46, 25-31. [CrossRef] [PubMed]

34. Piljac-Žegarac, J.; Valek, L.; Martinez, S.; Belščak, A. Fluctuations in the phenolic content and antioxidant capacity of dark fruit juices in refrigerated storage. Food Chem. 2009, 113, 394-400. [CrossRef]

35. Montoro, P.; Tuberoso, C.I.G.; Perrone, A.; Piacente, S.; Cabras, P.; Pizza, C. Characterisation by liquid chromatography-electrospray tandem mass spectrometry of anthocyanins in extracts of Myrtus communis 1. berries used for the preparation of myrtle liqueur. J. Chromatogr. A 2006, 1112, 232-240. [CrossRef] [PubMed]

36. Klimczak, I.; Małecka, M.; Szlachta, M.; Gliszczyńska-Świgło, A. Effect of storage on the content of polyphenols, vitamin $C$ and the antioxidant activity of orange juices. J. Food Compos. Anal. 2007, 20, 313-322. [CrossRef]

37. Re, R.; Pellegrini, N.; Proteggente, A.; Pannala, A.; Yang, M.; Rice-Evans, C. Antioxidant activity applying an improved ABTS radical cation decolorization assay. Free Radic. Biol. Med. 1999, 26, 1231-1237. [CrossRef]

38. Wrolstad, R.E.; Acree, T.E.; Decker, E.A.; Penner, M.H.; Reid, D.S.; Schwartz, S.J.; Shoemaker, C.F.; Smith, D.; Sporns, P. Anthocyanins. In Handbook of Food Analytical Chemistry; John Wiley \& Sons, Inc.: Hoboken, NJ, USA, 2005; pp. 5-69.

39. Tešević, V.; Nikićević, N.; Milosavljević, S.; Bajić, D.; Vajs, V.; Vučković, I.; Vujisić, L.; Dordević, I.; Stanković, M.; Veličković, M. Characterization of volatile compounds of "Drenja", an alcoholic beverage obtained from the fruits of Cornelian cherry. J. Serb. Chem. Soc. 2009, 74, 117-128. [CrossRef]

Sample Availability: Samples of the liqueurs are available from the authors. 